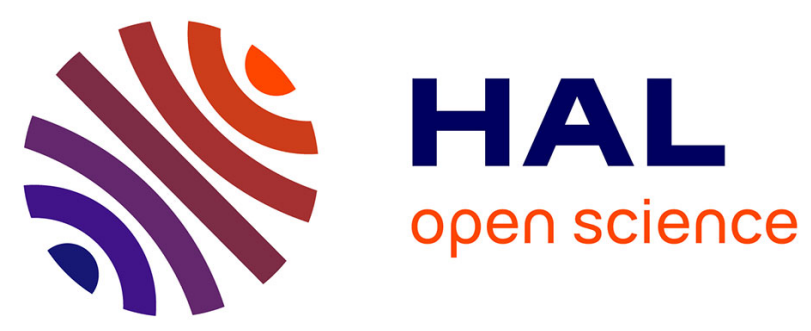

\title{
Modelling of a multi-zone building and assessment of its thermal behaviour using an energy simulation software
}

Sullivan Royer, Michaël Bressan, Stéphane Thil, Thierry Talbert

\section{To cite this version:}

Sullivan Royer, Michaël Bressan, Stéphane Thil, Thierry Talbert. Modelling of a multi-zone building and assessment of its thermal behaviour using an energy simulation software. 2013 IEEE International Conference on Automation Science and Engineering (CASE 2013), Aug 2013, Madison, WI, United States. pp.735-740, 10.1109/CoASE.2013.6653981 . hal-01292474

\section{HAL Id: hal-01292474 \\ https://hal.science/hal-01292474}

Submitted on 23 Mar 2016

HAL is a multi-disciplinary open access archive for the deposit and dissemination of scientific research documents, whether they are published or not. The documents may come from teaching and research institutions in France or abroad, or from public or private research centers.
L'archive ouverte pluridisciplinaire HAL, est destinée au dépôt et à la diffusion de documents scientifiques de niveau recherche, publiés ou non, émanant des établissements d'enseignement et de recherche français ou étrangers, des laboratoires publics ou privés. 


\title{
Modelling of a multi-zone building and assessment of its thermal behaviour using an energy simulation software*
}

\author{
Sullivan Royer ${ }^{1}$, Michaël Bressan ${ }^{1}$, Stéphane Thil $^{1}$ and Thierry Talbert ${ }^{1}$
}

\begin{abstract}
This paper deals with the modelling of a multizone university building in the town of Perpignan, in southern France. An energy simulation software (EnergyPlus) is used to create a model of the building's thermal behaviour. The building has been instrumented and the comparison between simulated and measured temperatures validates the obtained model.
\end{abstract}

\section{INTRODUCTION}

Following the Kyoto Protocol, the European Union is committed to reduce its greenhouse gases (GHGs) emissions by $8 \%$ between 2008 and 2012 compared to 1990. In France, the building sector accounts for $25 \%$ of national emissions of GHGs. In addition, still in France, the building sector is the largest consumer of energy among all economic sectors, with 70 million tons of oil equivalent, representing $44 \%$ (in 2011) of the total energy consumption. Its consumption has increased by almost $25 \%$ over the last 20 years.

In the United States (US), the buildings sector accounted for about $41 \%$ of primary energy consumption in 2010. Still in 2010, China has became the largest consumer of energy for $20 \%$ of world energy consumption forward the US for $19 \%$, Europe 15\%, Russia 6\% and others for $40 \%$ [1].

Improving energy efficiency in the building sector, that is reducing energy consumption while maintaining an equivalent level of performance, can help to stabilise GHGs emissions and is therefore an important research domain. As incentives, the French State has established a thermal law (RT 2012 [2]) and an 'energy performance diagnosis' (DPE) which evaluates the energy performance of a building by estimating annual consumption (in $\mathrm{kWh} / \mathrm{m}^{2} / \mathrm{year}$ ). Anticipating energy consumption helps avoiding peak demand while taking into account the needs of the occupants ([3], [4], [5]).

In this context, we have studied an university building, the Polytech Montpellier Renewable Energy engineering school, based in Perpignan (southern France). The goal of the project is to reduce the energy consumption by using advanced control strategies on the heating and cooling system. The first step is to obtain a model of the thermal behaviour of the building using an energy simulation software (here EnergyPlus). This model will then be used to assess the impact of building modifications (architecture, heating or cooling control, etc.) [6], [7] and also to generate data that

\footnotetext{
* This work is supported by a fund from the FUI (Fonds Unique Interministériel).

${ }^{1}$ Laboratoire PROMES-CNRS (UPR 8521), Tecnosud, Rambla de la thermodynamique 66100 PERPIGNAN, FRANCE firstname. lastnameepromes.cnrs.fr
}

would be hard or impossible to obtain from an operating building.

This article is organised as follows. Section II describes the building geometry and its Heating, Ventilation and AirConditioning (HVAC) system. Section III introduces the collected data from installed instrumentation, and how the local weather data from MeteoFrance is converted into a weather data file adapted to the building simulation software. The modelling of the studied building using EnergyPlus is presented in Section IV. Finally, the last part is the comparison between measurements and simulated data, which allows to validate the building simulation models.

\section{BUILDING DESCRIPTION}

\section{A. Geometry and materials}

The university building under study was built in 2008, and is home for the Polytech Montpellier Renewable Energy engineering school. It is located in the town of Perpignan, in southern France, and consists of two floors with almost the same configuration (see Figure 1). Each floor has an area of $257.45 \mathrm{~m}^{2}$; the total floor area of the building is thus $514.9 \mathrm{~m}^{2}$.

The ground floor is made up of two classrooms, a space for students, an office, a corridor and toilets. The first floor is identical, except that the student space and the office have been gathered into a media classroom. The student space and the office are north oriented, rotated about $15^{\circ}$ clockwise (see Figure 1). There is just one type of glazing installed in the building: a double glazing constituted by two clear glasses of $4 \mathrm{~mm}$ and a $12 \mathrm{~mm}$ air space between. Each window has an outside blind covering all of its glazed part. The blinds consist of flat, equally-spaced slats in polyvinyl chloride (PVC) that are manually controlled. Finally, as can be seen in the exterior photography of the building (Figure 2), the stairs are located outside the building.

\section{B. HVAC system}

The HVAC is a Hitachi Variable Refrigerant Flow (VRF) air conditioning system. It comprises several air handling units which are connected to an external condensing unit. As a result, the refrigerant flow can be varied either by using an inverter controlled variable speed compressor or by using more than one compressor (see Figure 3). The heat or cold production is performed by two outside condensing units (two tubes version: no simultaneous cooling and heating mode) and is supplied inside by the indoor units. These air to air heat pump units are made up of a ventilation group, which consist of one or two double inlet centrifugal impellers 

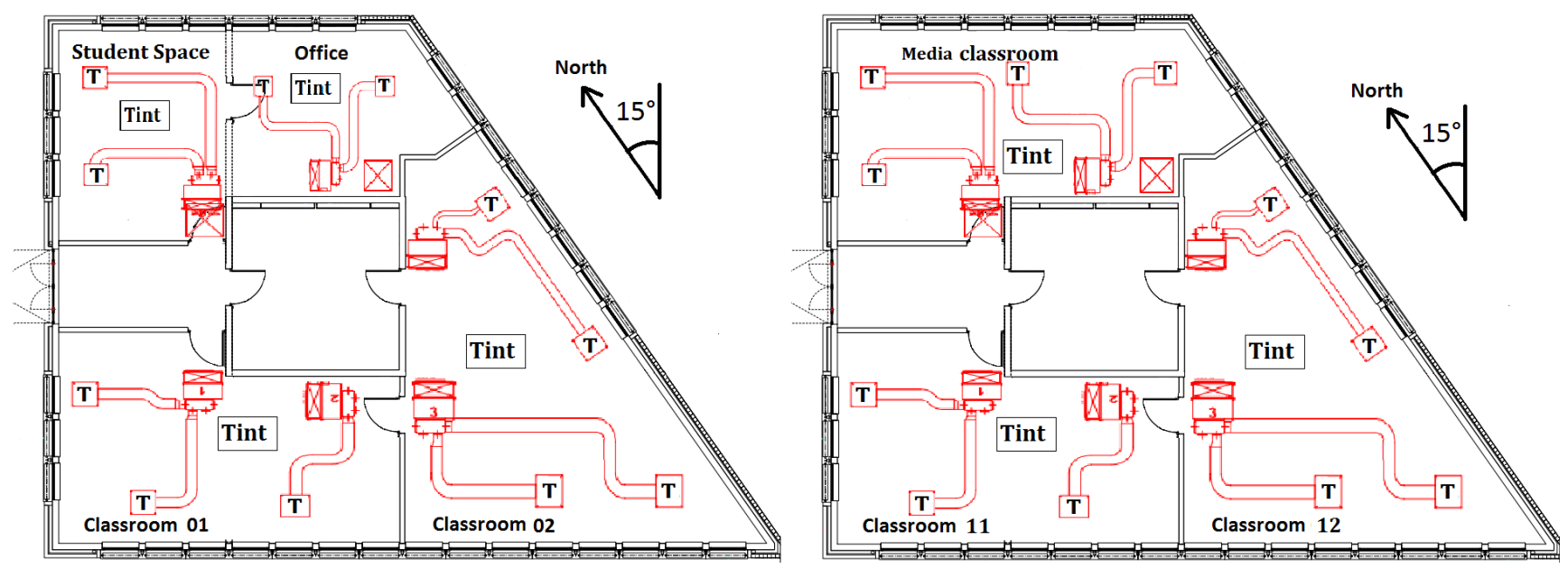

Fig. 1. Ground floor (left) and first floor (right) with HVAC and temperature sensors.

in aluminium. The indoor units are under manual control by wall thermostats in each room and have three air flow speeds (see Table I). Finally, there is a mechanical ventilation that operates during activity in classrooms and permanently in toilets.

\begin{tabular}{cccc}
\hline Speed & High & Medium & Low \\
\hline Air flow $\left(\mathrm{m}^{3} / \mathrm{min}\right)$ & 16 & 15 & 13 \\
\hline
\end{tabular}

TABLE I

AIR FLOW OF INDOOR UNITS.

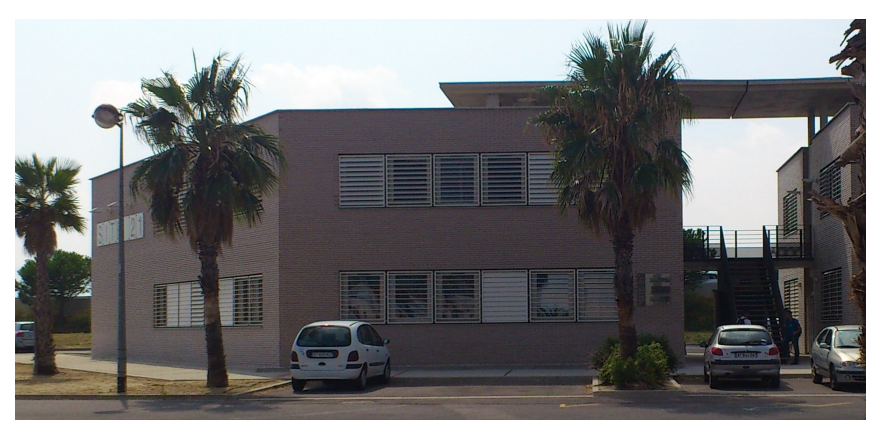

Fig. 2. The two floors building under study.

\section{Collected DATA}

\section{A. Instrumentation}

In order to assess the building thermal behaviour, it is necessary to collect data like room air temperature or supply air flow temperature. From this point, it will be possible to compare inside rooms actual temperature and simulated one. HVAC system and sensors location (denoted by a capital ' $T$ '), appear on the two stories building plans (Figure 1), while the sensor's features are listeed in Table II. Installed temperature sensors (LM35DZ) collect air flow temperature at each supply duct outlet and air temperature inside each room every five minutes.

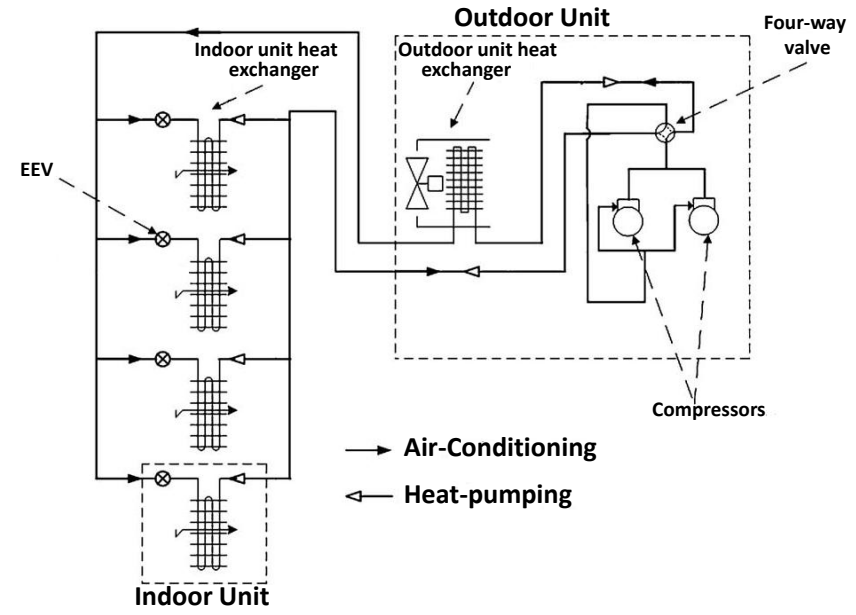

Fig. 3. Example of schematic diagram of a multi-split VRF system having four indoor units [8].

Sensors are wire-connected to an analog to digital converter, hence measures are gathered and converted into digital format, treated in frames and then transmitted by Xbee pro serie 1 modules to a Xbee receiver. There is one Xbee transmitter per room and one Xbee receiver per floor. These Xbeepro modules are used with an Application Programming Interface and are low consumers $(50 \mathrm{~mA}$ in reception) and use the IEEE 802.15.4 norm of the Zigbee Protocol [9]. Once frames are received, an Arduino micro-controller treat them one by one and convert values into ${ }^{\circ} \mathrm{C}$. The micro-controller also has an embedded server that can be used to display current temperature data. Finally, a central server in the building requests the embedded server by TCP/IP protocol, in order to store and plot collected temperatures in real time. Figure 4 displays the data acquisition and transmission architecture.

\section{B. Meteorological data}

In this work, we have used local weather data provided by the french meteorological organization MeteoFrance [10]. 


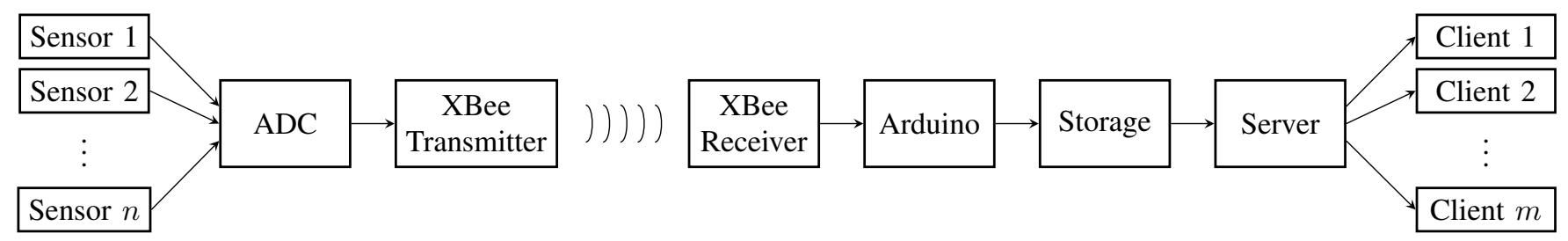

Fig. 4. Instrumentation and data transmission architecture.

\begin{tabular}{lr}
\hline Calibre & Celsius \\
Linear scale factor & $10 \mathrm{mV} /{ }^{\circ} \mathrm{C}$ \\
Accuracy & $0.5^{\circ} \mathrm{C}$ \\
Operating temperature range & $0{ }^{\circ} \mathrm{C}$ to $100^{\circ} \mathrm{C}$ \\
Low current drain (typical) & $60 \mu \mathrm{A}$ \\
Low self heating (typical) & $0.08^{\circ} \mathrm{C}$ \\
\hline
\end{tabular}

TABLE II

LM35DZ SENSORS MAIN FEATURES.

The meteorological station is near Perpignan's airport, located $10 \mathrm{~km}$ as the crow flies from the studied building. The main data needed to create a weather file for the energy simulation software EnergyPlus are temperatures, wind speed and direction, relative humidity, atmospheric pressure, solar radiations, precipitable water and visibility. They are all measured with a hourly time step and listed in Table III.

\begin{tabular}{lcc}
\hline $\begin{array}{l}\text { Parameter } \\
\text { description }\end{array}$ & $\begin{array}{c}\text { MeteoFrance } \\
\text { unit }\end{array}$ & $\begin{array}{c}\text { Required } \\
\text { unit }\end{array}$ \\
\hline Dry bulb temperature & ${ }^{\circ} \mathrm{C}$ & ${ }^{\circ} \mathrm{C}$ \\
Dew point temperature & ${ }^{\circ} \mathrm{C}$ & ${ }^{\circ} \mathrm{C}$ \\
Relative humidity & $\%$ & $\%$ \\
Atmospheric station pressure & $\mathrm{hPa}$ & $\mathrm{Pa}$ \\
Wind speed & $\mathrm{m} / \mathrm{s}$ & $\mathrm{m} / \mathrm{s}$ \\
Wind direction & $\circ$ & $\circ$ \\
Global horizontal radiation & $\mathrm{J} / \mathrm{cm}^{2}$ & $\mathrm{~W} / \mathrm{m}^{2}$ \\
Direct normal radiation & & $\mathrm{W} / \mathrm{m}^{2}$ \\
Diffuse horizontal radiation & & $\mathrm{W} / \mathrm{m}^{2}$ \\
Precipitable water & $\mathrm{mm}$ & $\mathrm{mm}$ \\
Visibility & $\mathrm{m}$ & $\mathrm{km}$ \\
\hline
\end{tabular}

TABLE III

Meteorological data From MeteoFrance AND ReQUiRed by ENERGYPLUS (BLANK LINES MEAN DATA ARE NOT PROVIDED).

The meteorological data can not be used directly; two measurements must be converted and two measurements are missing: direct normal radiation and diffuse horizontal radiation. Fortunately, these two radiations can be derived from the global horizontal radiation. In [11], eight models to compute diffuse fraction of global horizontal radiation for cities having the same latitude as Perpignan are compared. Three models providing similar results are more adequate for energy building simulation. Among these three models, the Erbs model [12] is used in this work. The method is briefly recalled (a description of the variables is given in Table IV).

First of all, extraterrestrial radiation $I_{0}$ is computed hourly using (1). It depends on the solar constant $I_{S C}$, zenith angle $\theta_{z}$ and the day number $n$ :

$$
I_{0}=I_{S C}\left(1+0.33 \cos \left(\frac{360 n}{365}\right)\right) \cos \theta_{z}
$$

The clearness index $k_{t}$, ratio of the global-to-extraterrestrial solar radiation on horizontal surface, is then deduced:

$$
k_{t}=\frac{I}{I_{0} \cdot \sin (\alpha)}
$$

Now, depending on the clearness index value, the diffuse fraction $k_{d}$ can be determined:

- if $k_{t} \leqslant 0.22$ :

$$
k_{d}=1-0.09 k_{t}
$$

- if $0.22 \leqslant k_{t} \leqslant 0.8$ :

$$
\begin{aligned}
k_{d}=0.95-0.16 k_{t}+4.39 k_{t}^{2} & \\
& -16.64 k_{t}^{3}+12.34 k_{t}^{4}
\end{aligned}
$$

- if $k_{t}>0.8$ :

$$
k_{d}=0.165
$$

Since the diffuse fraction is the ratio of the diffuse-to-global solar radiation, it can be calculated using:

$$
I_{d}=I \cdot k_{d}
$$

Finally, the direct radiation on a horizontal surface is given by:

$$
I_{b}=\frac{I_{n}}{\sin (\alpha)}
$$

where $I_{n}=I\left(1-k_{d}\right)$ is the normal direct radiation.

\begin{tabular}{ccc}
\hline Name & Description & Unit (or value) \\
\hline$I_{0}$ & Extraterrestrial radiation & $\mathrm{W} / \mathrm{m}^{2}$ \\
$I_{S C}$ & Solar constant & $1367 \mathrm{~W} / \mathrm{m}^{2}$ \\
$I$ & Global horizontal radiation & $\mathrm{W} / \mathrm{m}^{2}$ \\
$I_{d}$ & Diffuse horizontal radiation & $\mathrm{W} / \mathrm{m}^{2}$ \\
$I_{b}$ & Direct radiation on a horizontal surface & $\mathrm{W} / \mathrm{m}^{2}$ \\
$I_{n}$ & Normal direct radiation & $\mathrm{W} / \mathrm{m}^{2}$ \\
$\theta_{z}$ & Zenith angle & $\circ$ \\
$\alpha$ & Sun altitude & $\circ$ \\
$k_{t}$ & Clearness index & $\mathrm{n} / \mathrm{a}$ \\
$k_{d}$ & Diffuse fraction & $\mathrm{n} / \mathrm{a}$ \\
$n$ & Day number in the year & $\mathrm{n} / \mathrm{a}$ \\
\hline
\end{tabular}

TABLE IV

VARIABLES NEEDED TO COMPUTE DIRECT AND DIFFUSE RADIATIONS. 


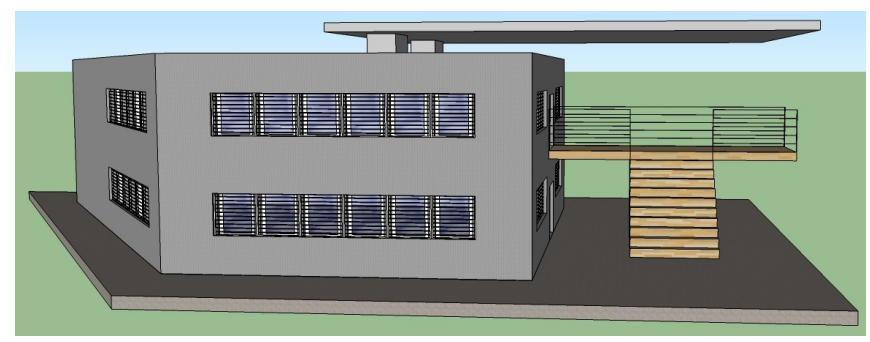

Fig. 5. Virtual building created with Google Sketchup.

\section{Modelling OF THE BUILDING}

The modelling of the building and his HVAC system are made with EnergyPlus (version 7), a building energy simulation software created by the US Department of Energy [13]. The virtual architecture of the building is created with the Google Sketchup 3D design software (Figure 5) and the Legacy OpenStudio plug-in [14]. The Legacy OpenStudio Plug-in for SketchUp allows to easily create and edit zones and surfaces in EnergyPlus input files.

\section{A. Building geometry and materials}

Building geometry is obtained from the architect book, where building materials and their thickness can also be found. However, thermal properties of used materials, such as density, conductivity, specific heat and others are not given and must be derived or approximated from literature [15].

Each classroom contains two interior units, while corridors and toilets do not have any. It is usual, in building simulation, to define one thermal zone per air supply unit; here this rule is not respected. Indeed, since all thermostats within a single room are set to the same temperature, it is possible to define just one zone per room. Each classroom or office is thus modelled as a single zone, and toilets and corridors are grouped to form a larger area (they have no air supply units). The building totals in this way five areas on the ground floor and four zones on the first floor (see Figure 1).

\section{B. HVAC}

This subsection contains a brief presentation of EnergyPlus model and some characteristics used to describe the HVAC Variable Refrigerant Flow system. Figure 6 shows objects and connections used by EnergyPlus.

Indoor units are made up of direct-expansion cooling and/or heating coils (see 'Zone HVAC Terminal Unit' in Figure 6). For this type of system, indoor units are part of a thermal zone via two nodes: the zone inlet and zone exhaust. Connections between indoor units and the two outdoor units - called AirConditioner:VariableRefrigerantFlow in EnergyPlus - are done through a zone terminal unit list indexing all these connections.

After the indoor and outdoor units, their internal equipment (such as fans, cooling and heating coils) are created. Parameters entered in the program for these objects came from the technical catalog provided by the manufacturer, except for the cooling and heating performance curves of indoor and outdoor units, which were missing. Thus, performance curves had to be created from similar equipment, found in [16].

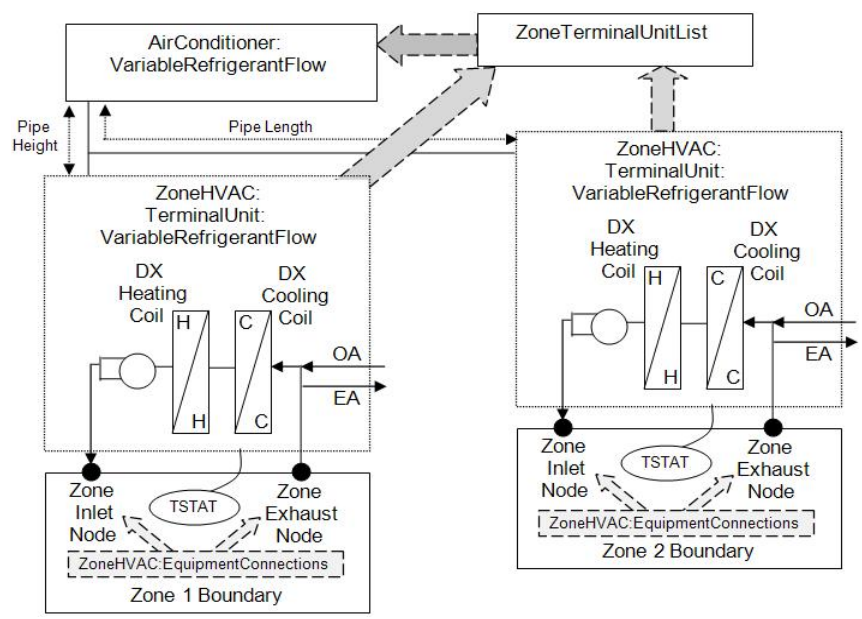

Fig. 6. Connection rules of a HVAC Variable Refrigerant Flow equipment in EnergyPlus [17] (example with two thermal zones).

\section{Model inputs/outputs}

The goal of this work is for the EnergyPlus model to simulate precisely the interior temperatures in each building zone, using the building's characteristics, weather data and HVAC inputs. The actual inputs of the model are thus weather and HVAC inputs, and the output is the indoor temperature in each zone (although heating or cooling electrical consumption, comfort index, or other meteorological parameters like global radiation can be plotted too). A summary diagram of the modelling method employed in this work can be found in Figure 7.

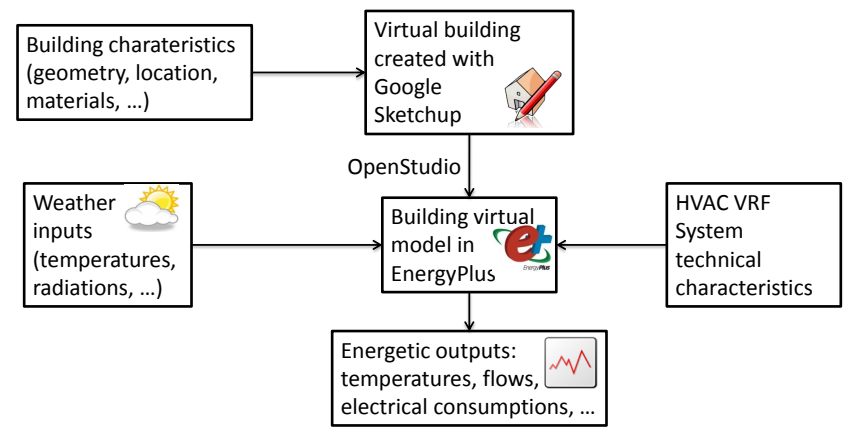

Fig. 7. Modelling method summary.

\section{MODEL VALIDATION AND DISCUSSION}

In order to validate the EnergyPlus model, simulated temperatures are compared to the actual measurements.

\section{A. Building envelope}

We first validate the building envelope. The test period was during summer 2012, from June 8th to July 10th, when the building was unoccupied. As a result, there was no HVAC 
and no internal gain to consider (lighting, electrical equipment, people occupation and activity). If successful, this test will then validate the thermal behaviour of the building model without any other disturbance than the weather.

The results obtained from classroom 11 and media room (see Figure 1 for the room configuration) appear on Figure 8, where only one month is plotted (the results being similar during the other month). In the two top subplots, the black curve represents the indoor temperature measurements while the magenta curve represents the simulated indoor temperature from EnergyPlus; the bottom subplot represents the outdoor temperature from MeteoFrance. Perceptible discontinuities on indoor temperature measurements come from missing data due to sensors or server failures.

Curves have globally the same variations, although their amplitude appear to be higher for the simulated temperature. One can notice rather large discrepancies between June 30th and July 2nd in classroom 11 and around June 24th in media room; these rooms were actually occupied by students and a council meeting during these periods. The standard deviation of the difference between simulated and measured temperatures is roughly $1^{\circ} \mathrm{C}$. The discrepancies between the curves thus fall in a range that can be accounted for by the sensors accuracy $\left(0.5^{\circ} \mathrm{C}\right)$ and the approximations made when detailed information on the building characteristics were unavailable. The model representing the building envelope is thus satisfying.

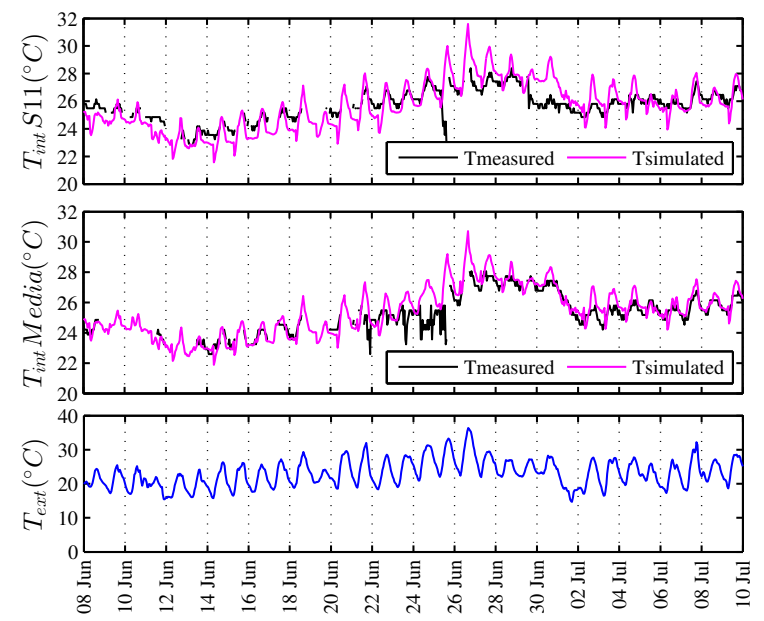

Fig. 8. Classroom 11, media room and outside air temperature, without any occupation or HVAC system (envelope test during summer).

\section{B. Building with HVAC system}

The second period when the building was unoccupied was during winter holidays, from December 22nd 2012 to January 7th 2013. This second test is conducted to validate the model of the building and its HVAC system as a whole.

The heating temperature setpoint was set to $19^{\circ} \mathrm{C}$. As in the previous test, only a few weeks are plotted instead of the whole period. The results are plotted in Figure 9: the black curve is the measured indoor temperature and the magenta curve the simulated indoor temperature. As before, the bottom subplot displays the outdoor temperature.

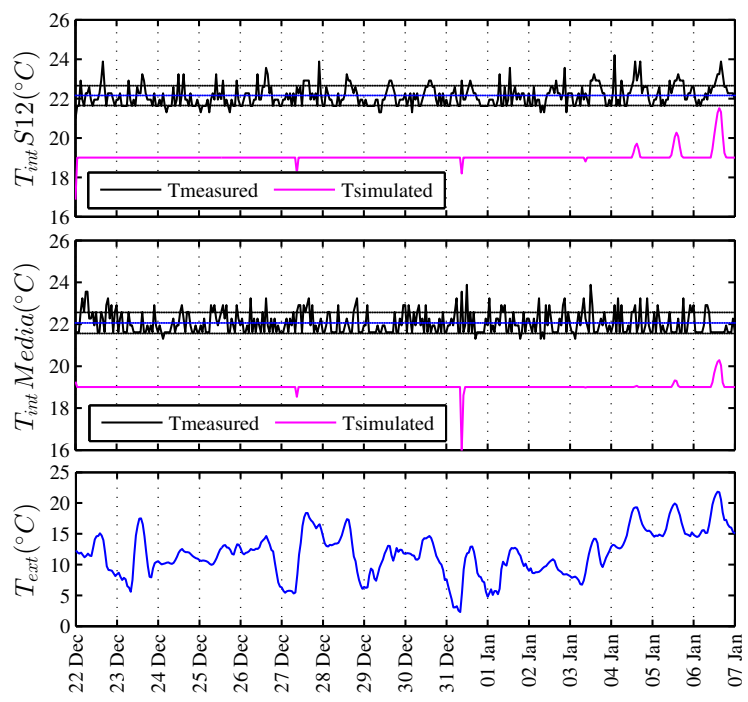

Fig. 9. Classroom 12, media room and outside air temperature, with HVAC system (winter test).

There are several things to be noticed.

- The simulated indoor temperature is, as expected, almost constant at $19^{\circ} \mathrm{C}$.

- The low peaks in the magenta curve around December 27th and 31st can be explained by two things: the HVAC system is probably a little undersized and those two days were cold (for the area) and blowy. This phenomena is amplified for the north-oriented media room.

- The high peaks in the magenta curve between January 4th and 7th are due to the rise of the outdoor temperature: the cooling coil was stopped in EnergyPlus during this test. This phenomena is amplified for the southoriented classroom 12.

- The mean of the measured indoor temperature is $22.06{ }^{\circ} \mathrm{C}$, to wit a difference of approximately $3{ }^{\circ} \mathrm{C}$ with the temperature setpoint of $19^{\circ} \mathrm{C}$. This is explained by the sensors location: they are level with the ceiling, at a distance of $2.70 \mathrm{~m}$ from ground and $1.30 \mathrm{~m}$ from the thermostat. According to references [15], [17], there is an allowable vertical temperature gradient of $2{ }^{\circ} \mathrm{C} / \mathrm{m}$ or $3^{\circ} \mathrm{C} / 1.5 \mathrm{~m}$, which corresponds the temperature difference.

- The measured indoor temperature is noisy: it fluctuates around a mean of $22.06{ }^{\circ} \mathrm{C}$ with a standard deviation of roughly $0.5^{\circ} \mathrm{C}$. This can be explained by the air unsteadiness at ceiling level; the three horizontal lines appearing in Figure 9 are the mean value with standard deviation equal to sensors accuracy.

The zone air temperature plotted in Figure 9 is an average: the zone heat balance is a 'well stirred' model [17]. Fortunately, it is possible to get EnergyPlus to output a temperature at any height in the considered zone in addition to the mean temperature. So, in order to plot the same temperatures, the thermostat height is set at the same level 
than the installed sensors. The results appear in Figure 10: the measured temperature is plotted in black, the simulated temperature at thermostat/sensor in cyan and the mean air temperature in magenta (that is simply obtained using a constant vertical temperature gradient of $2{ }^{\circ} \mathrm{C} / \mathrm{m}$ ). There is a good agreement between simulation and measurements, with similar variations, probably coming from air turbulence at ceiling level (exhaust and return air). Variations are around a mean temperature of $22.06^{\circ} \mathrm{C}$ for measured data and $22.11^{\circ} \mathrm{C}$ for simulated data at thermostat, with a standard deviation of their difference of roughly $0.65^{\circ} \mathrm{C}$. The EnergyPlus model with HVAC system thus gives satisfying results.

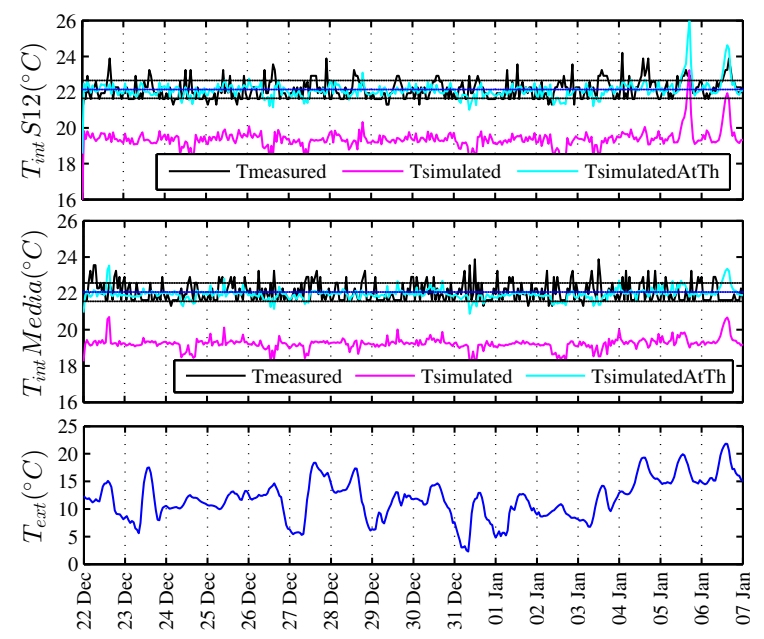

Fig. 10. Classroom 12, media room and outside air temperature, with HVAC system and a $2.0^{\circ} \mathrm{C} / \mathrm{m}$ vertical temperature gradient (winter test).

\section{CONCLUSION AND PERSPECTIVES}

Modelling a building thermal behaviour using an energy simulation software is time consuming. The main issue is the data gathering. Indeed, softwares like EnergyPlus require a lot of information: architecture, materials used and their thermal properties (conductivity, density, specific heat, ...), the glazing material specifications such as solar transmittance, solar reflectance and visible reflectance, etc. More often than not assumptions have to be made, based on usual cases and literature. Moreover, even with the architect book, there are differences between materials used and quoted, differences between plans and actual building. Also - although this is not particular to energy simulation softwares -, simulation results depend critically on weather data, which can be hard to find, incomplete.

Nonetheless, when gathering all these informations is possible, the energy simulation software gives accurate results, in good agreement with measurements. In this work, the building envelop model and the building HVAC model are satisfying. The simulation accuracy may be improved using more accurate meteorological data; to this end, a meteo station will be installed on the building's roof. Also, the building's infiltration could be measured. In this work, the value of infiltration parameters were copied from ressembling EnergyPlus examples.

Future work will use this model to generate data that will in turn be used to identify a parametric model of the building. Indeed, data collected during normal activity of the building is usually not informative enough (see persistence of excitation in e.g. [18]) to obtain a reliable model from system identification techniques [6]. Model predictive control techniques will then be used to optimise the energy efficiency of the building.

\section{ACKNOWLEDGEMENT}

The authors would like to thank Polytech Montpellier and Pyrescom for their involvement in this project, and also the french meteorological organization 'MeteoFrance', who provided weather data.

\section{REFERENCES}

[1] 2011 Buildings Energy Data Book. U.S. Department of Energy, March 2012.

[2] Réglementation thermique 2012: un saut énergétique pour les bâtiments neufs. Ministère de l'Écologie, du Développement durable, des Transports et du Logement, Avril 2011.

[3] ADEME, Ed., Les chiffres clés du bâtiment, ser. Énergie - Environnement, www.ademe.fr, 2011.

[4] "Efficacité énergétique et bâtiments," Connaissance des énergies, pp. $1-4$, December 2011.

[5] Y. Ma, A. Kelman, A. Daly, and F. Borrelli, "Predictive control for energy efficient buildings with thermal storage: Modeling, stimulation, and experiments," IEEE Control Systems Magazine, vol. 32, no. 1, pp. 44-64, 2012.

[6] S. Privara, Z. Vana, D. Gyalistras, J. Cigler, C. Sagerschnig, M. Morari, and L. Ferkl, "Modeling and identification of a large multi-zone office building," in IEEE International Conference on Control Applications (CCA), 2011, pp. 55-60.

[7] W.-J. Suh, C.-S. Park, and D.-W. Kim, "Application of a whole building simulation tool for a real-life buidling," in 12th Conference of International Building Performance Simulation Association, November 2011.

[8] T. N. Aynur, "Variable refrigerant flow systems: A review," Energy and Buildings, vol. 42, no. 7, pp. $1106-1112,2010$.

[9] Digi International, Inc., XBee $\mathrm{\AA} / X$ Xee-PRO $\mathrm{R}$ RF Modules, 2009.

[10] [Online]. Available: http://france.meteofrance.com/france/accueil

[11] S. Dervishi and A. Mahdavi, "Computing diffuse fraction of global horizontal solar radiation: A model comparison," Solar Energy, vol. 86, no. 6, pp. 1796 - 1802, 2012.

[12] D. Erbs, S. Klein, and J. Duffie, "Estimation of the diffuse radiation fraction for hourly, daily and monthly-average global radiation," Solar Energy, vol. 28, no. 4, pp. 293 - 302, 1982.

[13] U.S. Department of Energy, "EnergyPlus, Energy simulation software."

[14] National Renewable Energy Laboratory, "Legacy OpenStudio Plug-in for SketchUp."

[15] ASHRAE Handbook Fundamentals. American Society of Heating, Refigerating and Air-Conditioning Engineers, Inc., 2009.

[16] R. Raustad, Creating Performance Curves for Variable Refrigerant Flow Heat Pumps in EnergyPlus, F. S. E. Center, Ed. Florida Solar Energy Center/University of Central Florida, November 2012.

[17] U.S. Department of Energy, The encyclopedic reference to EnergyPlus input and output, October 2011.

[18] L. Ljung, System Identification: Theory for the User, 2nd ed., ser. Prentice Hall Information And System Sciences. Englewood Cliffs: Prentice Hall, 1999. 